from society, we endanger society, while to the extent that we maintain AIDS infected persons within society, we protect society. This is the message of realism and of tolerance." ${ }^{5}$ Mann argued that HIV could never be successfully addressed if impositions on human rights led people to hide their infections rather than seek testing and treatment. Only policy approaches that recognized and protected human rights (including the rights to treatment and care, gender equality, and education) would permit successful clinical and population-based interventions.

These complementary innovations are at the core of what we now call "global health" which has demonstrated its capacity to be far more integrative than traditional notions of international health. It draws together scientists, clinicians, public health officials, researchers, and patients, while relying on new sources of funding, expertise, and advocacy. This new formulation is distinct, first of all, in that it recognizes the essential supranational character of problems of disease and their amelioration and the fact that no individual country can adequately address diseases in the face of the movement of people, trade, microbes, and risks. Second, it focuses on deeper knowledge of the burden of disease to identify key health disparities and develop strategies for their reduction. Third, it recognizes that people affected by disease have a crucial role in the discovery and advocacy of new modes of treatment and prevention and their equitable access. Finally, it is based on ethical and moral values that recognize that equity and rights are central to the larger goals of preventing and treating diseases worldwide.

For more than the past decade, major academic medical centers, schools of public health, and universities have created global health programs and related institutes for multidisciplinary research and education. Thus, the institutionalization of this formulation is not only affecting services worldwide, but also changing the training of physicians, other health professionals, and students of public health. When the history of the HIV epidemic is eventually written, it will be important to recognize that without this epidemic there would be no global health movement as we know it today.

Disclosure forms provided by the author are available with the full text of this article at NEJM.org.

From the Department of the History of Science, Harvard University, Cambridge, MA, and the Department of Global Health and Social Medicine, Harvard Medical School, Boston.

1. Rosenberg CE. Disease and social order in America: perceptions and expressions. Milbank Q 1986;64:Suppl 1:55. abstract.

2. Brandt AM, Gardner M. Antagonism and accommodation: interpreting the relationship between public health and medicine in the United States during the 20th century. Am J Public Health 2000;90:707-15.

3. Cohen MS, Chen YQ, McCauley M, et al. Prevention of HIV-1 infection with early antiretroviral therapy. N Engl J Med 2011;365: 493-505.

4. Killen J, Harrington M, Fauci AS. MSM, AIDS research activism, and HAART. Lancet 2012;380:314-6.

5. Mann JM. Statement at an informal briefing on AIDS to the 42nd session of the United Nations. J R Stat Soc [A] 1988;151:131-6.

DOI: 10.1056/NEJMp1305297

Copyright $\odot 2013$ Massachusetts Medical Society.

\title{
War and Sexual Violence - Mental Health Care for Survivors
}

Charlotte Watts, Ph.D., Mazeda Hossain, M.Sc., and Cathy Zimmerman, Ph.D.

Related article, p. 2182

T here has been growing international concern about rape in fragile or volatile countries, especially those involved in armed conflicts; indeed, this concern has inspired the United Nations Security Council to issue nine sexual-violence-related resolutions since $2000 .^{1}$ Sexual violence is a human-rights abuse that often results in severe health consequences, including acute and longer-term psychological problems, such as depression, anxiety, and post-traumatic stress disorder (PTSD). In addition to the short- and long-term effects on survivors and their families, the aftermath of widespread sexual violence can affect the community at large. A pressing challenge is therefore to determine how to help survivors and communities overcome the psycho- logical effects of large-scale exposure to sexual violence and the other traumatic events that commonly occur in war-torn states.

Postconflict reconstruction efforts have traditionally focused on security, health, physical infrastructure, and economic development; they have been less well-equipped to respond to or prevent sexual and other forms of violence against women. Although 
there are established models of post-rape counseling used in high-income countries, questions remain about the feasibility and effectiveness of transferring such approaches to low-resource, conflict-affected settings. Social and cultural influences, low literacy levels, scarcity of trained mental health specialists, and the limitations of health systems in wartorn areas are only a few of the many challenges associated with meeting the widespread mental health needs of conflict-affected populations.

Many agencies working in conflict settings seek to provide psychosocial support to survivors of sexual violence, but to date, there have been virtually no rigorous impact assessments of these services. A trial by Bass et al. conducted in the eastern Democratic Republic of Congo (DRC) and reported on in this issue of the Journal (pages 21822191) offers promising evidence that an adaptation of group cognitive processing therapy (CPT) can be delivered effectively to women who have been exposed to sexual violence. The intervention, targeted at women who had either been raped or witnessed rape and who had symptoms indicative of depression, PTSD, and functional impairment, appeared to lead to greater improvements in mental health than did provision of case management and individual support.

Given the high rates of sexual violence globally, and especially in conflict-affected countries such as the DRC, this finding is very important. Although population data on the extent of sexual violence are extremely difficult to compile, data from the DRC suggest that it is prevalent: $16 \%$ of women surveyed in a national Demographic and Health Survey in 2007 reported experiencing sexual violence at some point in their lives. Other studies document prevalences ranging from 18 to $40 \%$ among women and 4 to $24 \%$ among men ${ }^{2,3}$ (the variations may be due in part to actual variations in exposure and in part to methodologic and definitional differences). Recent estimates suggest, for example, that approximately 1150 women in the DRC are raped per day. ${ }^{4}$

Although the high levels of sexual violence in the DRC have led to growing international dialogue, rape during war is not unique to the DRC; indeed, it affects many, if not most, countries that are at war, including several African states and, more recently, countries in the Middle East. The table shows the prevalence of sexual violence in three conflict-affected sub-Saharan African countries, where 16 to $22 \%$ of women have ever experienced sexual violence and 4 to $18 \%$ reported having been assaulted in the previous year.

To understand the implications of the findings from the DRC study, we must also consider conflict-related sexual violence within the broader context of inequality between the sexes and other forms of gender-based violence. In the DRC, women also report high levels of violence by intimate partners, with $35 \%$ of women who have ever had a partner reporting having experienced sexual violence at the hands of a partner and 57\% reporting physical violence by a partner. ${ }^{5}$ In our research in Ivory Coast, another West African country affected by armed conflict, we see a similar pattern, with a high prevalence of violence from intimate partners, family members, and acquaintances. Similarly, the prevalence data in the table include sexual violence by women's partners. These data show that rape during war is only one of many forms of interpersonal violence experienced by women during armed conflicts. Sexual and physical violence by partners, child sexual abuse, rape by noncombatants, and other traumatic, life-threatening events are all major concerns.

Given that these other events also have severe mental health effects, it is important to ensure that resources supporting mental health services for sexual violence survivors do not inadvertently result in care that is exclusionary (i.e., only for survivors of conflict-related sexual violence). Though it may be tempting to focus service provision on women who appear to have experienced some of the most extreme forms of abuse, narrowly targeting mental health services toward survivors of sexual violence by combatants, for example, raises serious ethical questions, since it may exclude others in similar need of support, as well as potentially stigmatizing the targeted users.

Indeed, the risk of stigma and other negative implications of rape are major concerns for those seeking to respond to sexual violence. Bass et al. also describe study participants' concerns about abandonment and rejection by family and friends and about providing for themselves and their families, as well as their fears and stigmatization. The researchers also note that the greatest loss to follow-up occurred among older women, pregnant women, and 


\begin{tabular}{|c|c|c|c|c|}
\hline \multirow[t]{3}{*}{ Country } & \multirow[t]{3}{*}{ Study $\mathrm{Yr}$} & \multirow[t]{3}{*}{ Period of Armed Conflict } & \multicolumn{2}{|c|}{ Prevalence of Sexual Violence } \\
\hline & & & $\begin{array}{l}\text { Ever Sexually } \\
\text { Assaulted }\end{array}$ & $\begin{array}{l}\text { Sexually Assaulted } \\
\text { in Past } 12 \mathrm{Mo}\end{array}$ \\
\hline & & & \multicolumn{2}{|c|}{ percent } \\
\hline Democratic Republic of Congo & 2007 & 1998-present & 16.0 & 4.2 \\
\hline Liberia & 2007 & 1980-2003 & 17.6 & 10.8 \\
\hline Rwanda & 2010-2011 & 1990-2002 & 22.3 & 17.5 \\
\hline
\end{tabular}

women who had witnessed or experienced a wide range of traumatic events. Services should therefore be highly sensitive to the particular needs and vulnerabilities of such survivors of violence. CPT should be provided as part of a broader set of psychosocial and economic services.

Questions of the replicability and generalizability of the trial findings to other settings and populations remain. However, these new results suggest that it may be feasible to offer relatively specialized counseling services after sexual assault to women in low-resource, conflict-affected settings. Although the current study provides evidence about the effectiveness of CPT among women, it is important to note that men, boys, and girls also experience sexual violence and other traumatic events associated with conflict. For this reason, the findings should serve as a starting point for further exploration of CPT and other models of psychosocial support and counseling in these settings.

Even as we pursue this necessary search for effective, scalable methods of providing psychological support to populations exposed to terrorizing and lifealtering events, we should exercise caution in rolling out various techniques. Mental health has local, social, and cultural aspects that influence the acceptability and effectiveness of psychological support in different groups. Although treating psychiatric disorders is essential, service providers adopting various promising techniques for addressing post-trauma reactions must be careful not to allow interventions to pathologize, distress, or inadvertently stigmatize people who may already feel (and be) marginalized.

Overall, Bass et al. and their partner institutions are to be congratulated for their clear commitment to providing strong, targeted mental health services for women exposed to sexual violence in the DRC - a difficult setting in which to conduct such a rigorous evaluation trial. For decision makers and programs that aim to address violence against women in conflict-affected settings, we hope this study will be the beginning of a growing evidence base and informed action to improve the safety, health, and well-being of women, men, and children. Such responses are fundamental to achieving the international community's commitments to address sexual violence in conflict and are integral to the successful reconstruction of war-torn communities.

Disclosure forms provided by the authors are available with the full text of this article at NEJM.org.

From the London School of Hygiene and Tropical Medicine, London.

1. Action against sexual and gender-based violence: an updated strategy. United Nations High Commissioner for Refugees, 2011.

2. Duroch F, McRae M, Grais RF. Description and consequences of sexual violence in Ituri province, Democratic Republic of Congo. BMC Int Health Hum Rights 2011;11:5.

3. Johnson K, Scott J, Rughita B, et al. Association of sexual violence and human rights violations with physical and mental health in territories of the Eastern Democratic Republic of the Congo. JAMA 2010;304:553-62.

4. Peterman A, Palermo T, Bredenkamp C. Estimates and determinants of sexual violence against women in the Democratic Republic of Congo. Am J Public Health 2011; 101:1060-7.

5. MEASURE Demographic and Health Surveys. Calverton, MD: Macro International, 2007-2012.

DOI: 10.1056/NEJMp1304712

Copyright @ 2013 Massachusetts Medical Society. 